RESEARCH ARTICLE

\title{
Evaluation of the Effects of Monoblock and Twin Force Appliances on the Dentofacial System
}

\author{
Abdurahman Küçükönder ${ }^{1 *}$ and Cenk Doruk ${ }^{2}$ \\ ${ }^{1}$ Department of Orthodontics, Sutcu Imam University, Turkey \\ ${ }^{2}$ Department of Orthodontics, Cumhuriyet University, Turkey
}

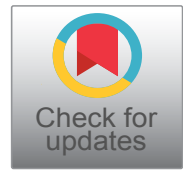

*Corresponding author: Abdurahman Küçükönder, Assistant Professor, Faculty of Dentistry, Department of Orthodontics, Sutcu Imam University, 46000 Campus, Kahramanmaras, Turkey

\begin{abstract}
Aim: The aim of this study was to evaluate the dentofacial effects of Monoblock and Twin Force appliances used in Class II Division 1 cases.

Methods: Twenty patients who were referred to our clinics were selected for our study. These patients were randomly allocated to each of the two functional appliance groups. Of these, 10 were treated with Monoblock and the remaining 10 were treated with Twin Force appliances. The inclusion criteria were as follows: Class II division 1 malocclusion, retrognathic mandible, peak growth period, normal or lowangle growth pattern and increased overjet. Pre-treatment and posttreatment cephalograms were obtained to evaluate the dentofacial changes. The intra-group comparisons were determined with paired samples $t$-test, while the inter-group comparisons were determined with students $t$-test at the significance level of $p<0.05$.
\end{abstract}

Results: It was revealed both appliances increased mandibular growth, helped enhancement of the effective mandibular length and had a restricting growth effect on the maxilla.

Conclusions: While the Monoblock appliance was more advantageous in cases where the skeletal effect ratio was higher because the dental effects of the Twin Force appliance were greater than that of the Monoblock appliance, the Twin Force appliance was a more effective choice in case of lack of cooperative operation of the patient's mobile functional appliance.

\section{Keywords}

Functional treatment, Monoblock, Twin force

\section{Introduction}

Class II malocclusions are common anomalies in the orthodontic practice. Orthodontists are interested in these because of the diversity of methods of diagnoses and approaches. Class II Division 1 malocclusions are the most common malocclusions, and Sayin, et al. [1] reported a $19 \%$ incidence of this malocclusion in their study. Class II malocclusions are often treated by stimulating mandibular growth, inhibiting maxillary growth, or both [2]. Some researchers studied the underlying skeletal incompatibility during growth modification, while others focused on the dental camouflage of jaw discrepancy [3].

Orthopedic treatment of malocclusions originating from the retrognathic mandible maybe performed with functional appliances that stimulate mandibular advancement [4]. Functional appliances are divided into two groups as removable and fixed functional appliances. Removable functional appliances maybe inserted and removed by the patient. The Monoblock appliance is the most commonly used removable appliance.

The most important advantage of fixed functional appliances is that they are independent of patient cooperation [5]. Fixed functional appliances have been used in patients with retrognathic mandibles for many years [2]. One of the most popular of these appliances is the Twin Force appliance.

In our study, the effects of Monoblock and Twin Force appliances on dentofacial structures were assessed in patients with Class II Div. 1 malocclusions.

\section{Materials and Methods}

The approval of the Clinical Research Ethics

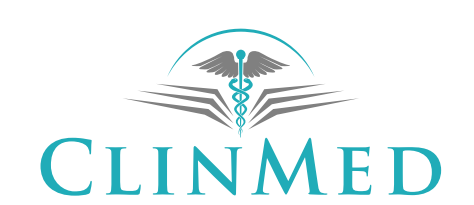

INTERNATIONAL LIBRARY

Citation: Küçükönder A, Doruk C (2019) Evaluation of the Effects of Monoblock and Twin Force Appliances on the Dentofacial System. Int J Oral Dent Health 5:078. doi.org/10.23937/2469-5734/1510078 Accepted: January 26, 2019: Published: January 28, 2019

Copyright: (c) 2019 Küçükönder A, et al. This is an open-access article distributed under the terms of the Creative Commons Attribution License, which permits unrestricted use, distribution, and reproduction in any medium, provided the original author and source are credited. 


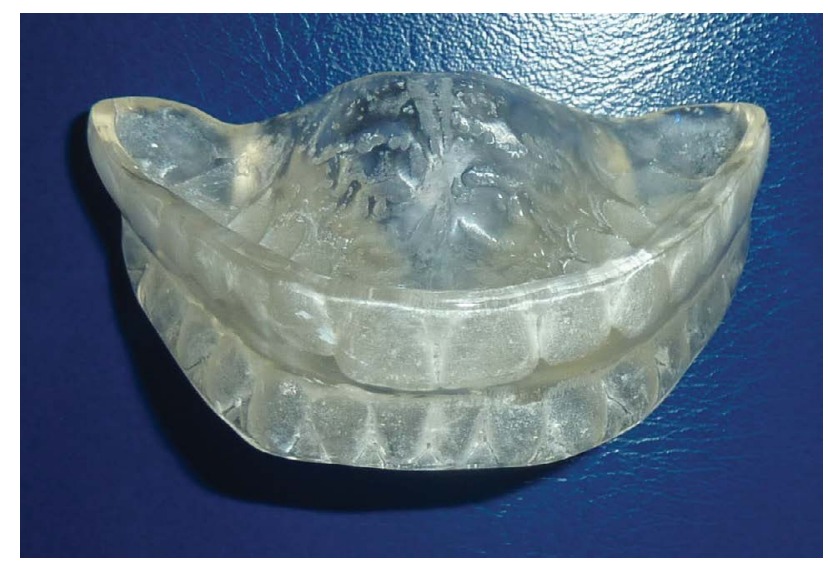

Figure 1: Monoblock appliance.

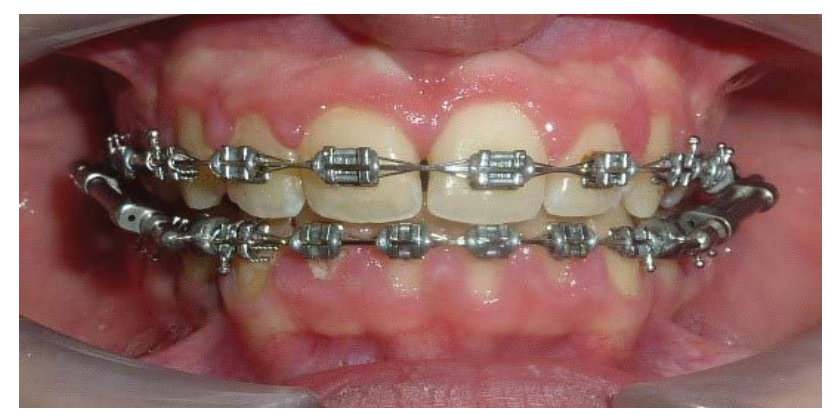

Figure 2: Front view of the Twin Force appliance in the patient's mouth.

Committee of the \#\#\# University (No: 2016-09/06) and the consent of the legal guardians of the patients were obtained before starting the study. When $\alpha=0.05 \beta=$ $0.20(1-\beta)=0.80$ was taken, and it was decided to take 10 individuals in each group. The power of the test was found as $P=0.80248$. This study was conducted with 20 patients with Class II Div. 1 malocclusions who applied for treatment to our clinics and were in need of functional treatment.

The selection criteria were as follows: Class II Div. 1 malocclusion, retrognathic mandible (ANB $>4^{\circ}$ ), peak growth period (MP3 cap), normal or low-angle growth pattern, $\left(\mathrm{SN} / \mathrm{MP}<40^{\circ}\right)$ and increased overjet (Overjet $>5 \mathrm{~mm}$ ). Hand and wrist radiographs were obtained from all patients to determine their growth period. The patients were noticed for being in the MP3 cap period.

Twenty patients who were referred to our clinics were selected randomly for our study. These patients were randomly allocated to one of the two functional appliance groups. Of these, 10 were treated with a Monoblock appliance, and the remaining 10 were treated with a Twin Force appliance.

\section{Appliance Design and Application}

\section{Monoblock}

All the Monoblock appliances were produced as premolar width sagittal and a 2-3 $\mathrm{mm}$ of vertical activation (Figure 1).

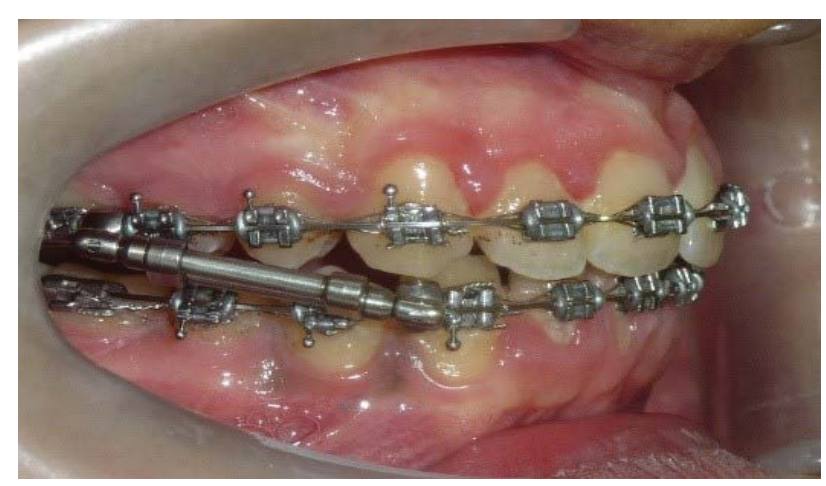

Figure 3: Lateral view of the Twin Force appliance in the patient's mouth.

The patients and their parents were informed about how to use the appliance, how to clean it and what to look for. It was stated that the patient should wear the appliance regularly except while eating. The patients were called for monthly checkups. In these checkups, the mandible was examined for protraction in the sagittal plane. At the end of the treatment, molar and canine class I relationships were established. The Monoblock appliance was removed, and the patient's film and photo records were renewed in the same session.

\section{Twin force}

Twin Force (Ortho Organizers Inc, Carlsbad, Calif) includes two nickel titanium coil springs that apply an average force of 200 grams on each side (Figure 2 and Figure 3).

The Roth-preadjusted brackets that included 0.018 0.025 -inch slots were bonded to the teeth. When the upper and lower arches were aligned, $0.017 \times 0.025$ inch rectangular stainless-steel arc-wires were installed. Both arc-wires were cinched back.

The appliance was fixed to the arc-wire at the mesial of the maxillary molars and to the arc wire at the distal of the mandibular canines.

The patients were called for monthly checkups. At the end of the $5^{\text {th }}$ month of treatment, the patients had a super class I relationship, the Twin Force appliance was removed, and the patient's film and photo records were renewed in the same session.

\section{Cephalometric analysis}

The tracery analysis of the lateral cephalograms was performed by using the Dolphin Imaging version 11.8 software.

The analyses that could not be carried out in the Dolphin 11.8 software were conducted by drawing with a lead pencil with a $0.3 \mathrm{~mm}$ tip on the paper.

While the SN plane was used as the horizontal reference plane, the SV plane was used as the vertical reference plane.

19 landmarks were used, and 34 measurements 


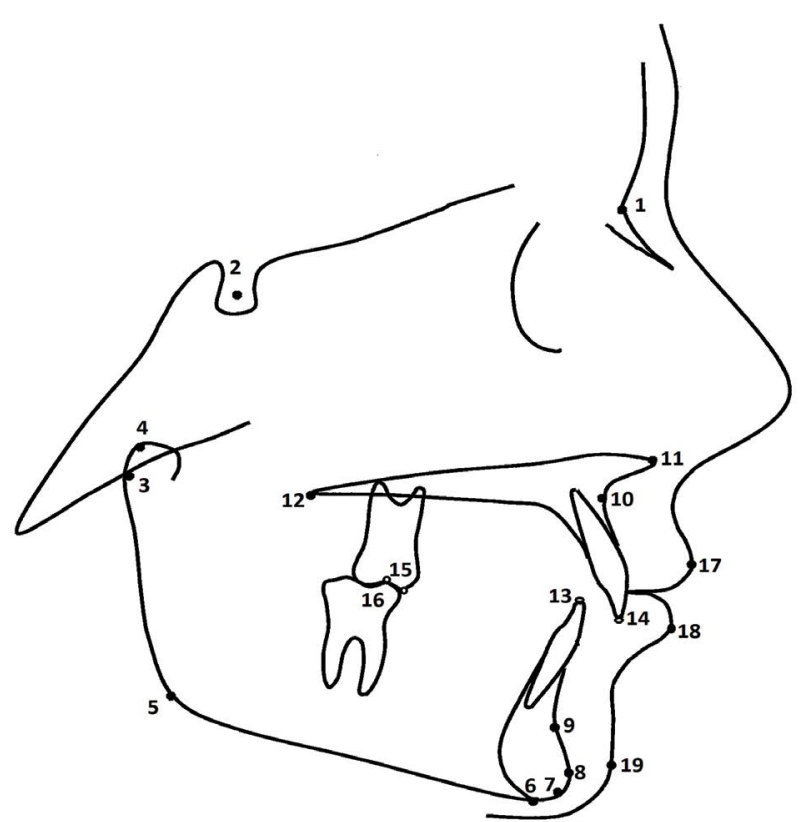

Figure 4: The cephalometric points: 1) Nasion (N); 2) Sella (S); 3) Artikulare (Ar); 4) Condylion (Co); 5) Gonion (Go); 6) Menton (Me); 7) Gnathion (Gn); 8) Pogonion (Pog); 9) B Point (B); 10) A Point (A); 11) Spina nasalis anterior (ANS); 12) Spina nasalis posterior (PNS); 13) Lower incisor incisal edge (li); 14) Upper incisor incisal edge (Is); 15) Upper molar mesial cusp tip (Mst); 16) Lower molar mesial cusp tip (Mit); 17) Upper lip (Ls); 18) Lower lip (Li); 19) Soft tissue pogonion (St Pog).

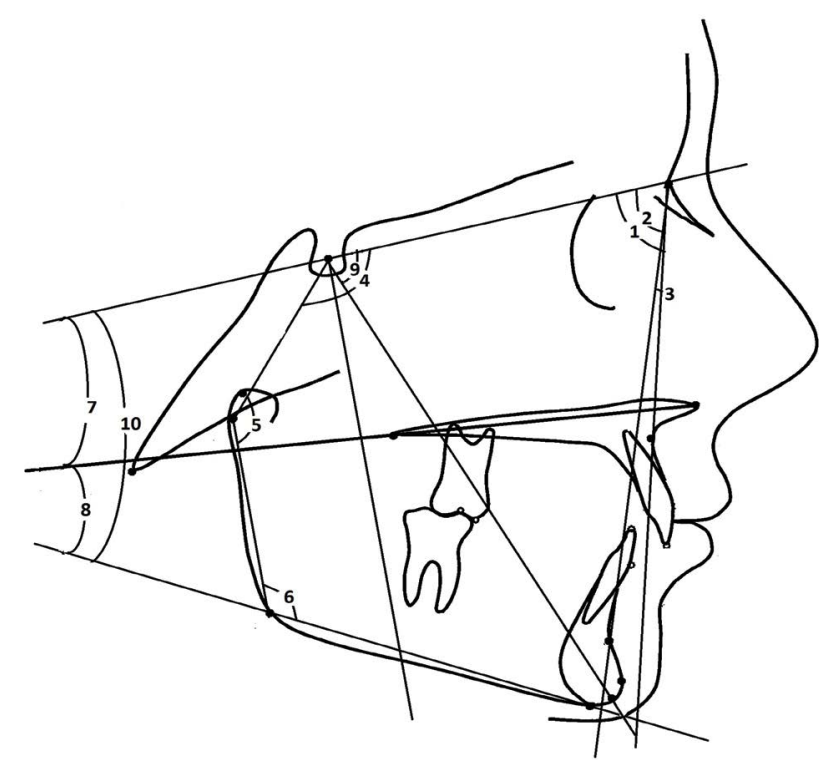

Figure 5: Skeletal angular measurements: 1) SNA; 2) SNB; 3) ANB; 4) Sella angle; 5) Articular angle; 6) Gonial angle; 7) SN/PP; 8) SN/MP; 9) PP/MP; 10) Y-axis angle.

were estimated on the lateral cephalograms (Figure 4, Figure 5, Figure 6, Figure 7 and Figure 8). Cephalometric measurements were conducted by the Research Assistant Abdurahman KÜÇÜKÖNDER. The measurement error was calculated with the Dahlberg formula with a precision of $0.5^{\circ}$ or lower millimeters.

\section{Statistical analysis}

When the parametric test assumptions (Kolmog-

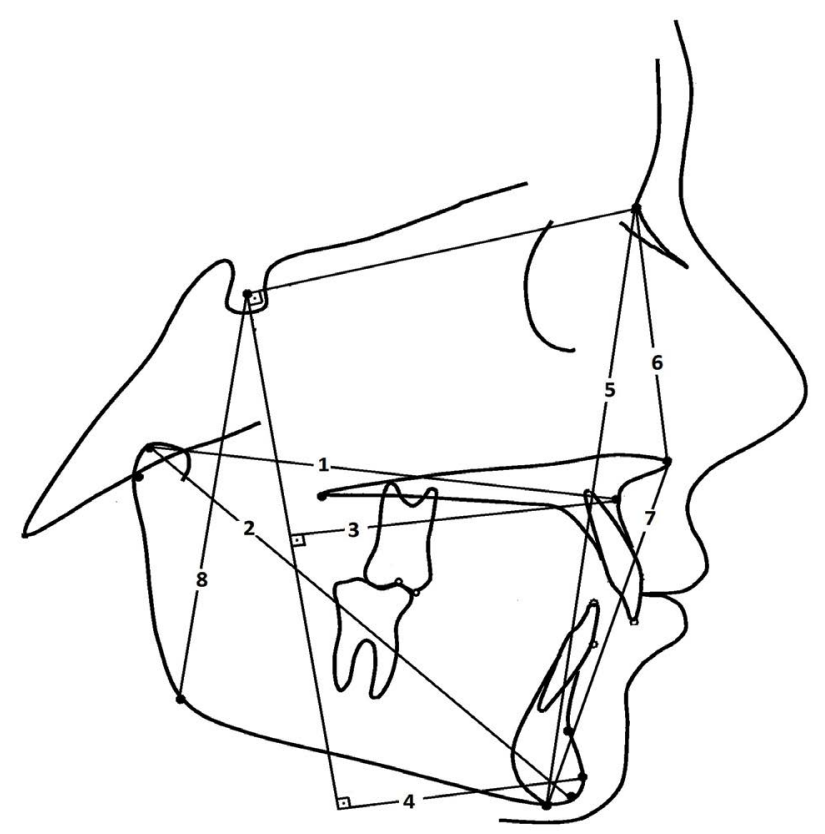

Figure 6: Skeletal linear measurements: 1) Co-A; 2) CoGn; 3) A-SV; 4) Pog-SV; 5) N-Me; 6) N-ANS; 7) ANS-Me; 8) S-Go.

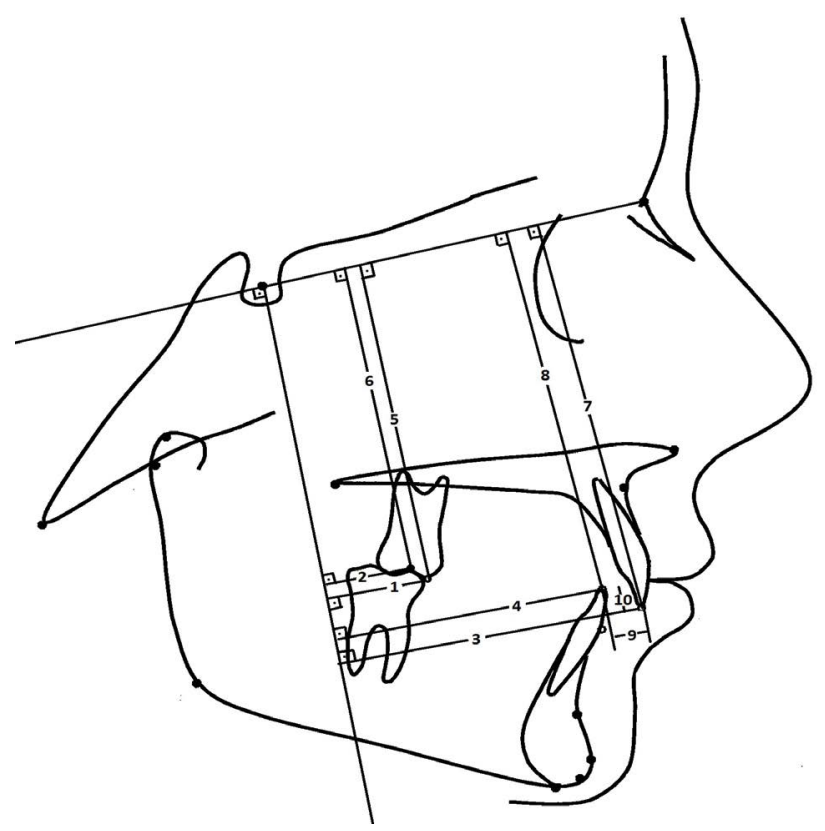

Figure 7: Dental linear measurements: 1) Mst-SV; 2) MitSV; 3) Is-SV; 4) li-SV; 5) Mst-SN; 6) Mit-SN; 7) Is-SN; 8) li-SN; 9) Overjet; 10) Overbite.

orov-Smirnov) were fulfilled in evaluating the data by loading the data obtained from our study into the SPSS (Ver: 22.0) program, the significance test between the two means and the significance test between the spouses, when the parametric test assumptions were not met, Mann Whitney U, Wilcoxon test and Chi-Square test were used, and the error level was taken as 0.05 .

\section{Results}

The evaluation of the mean values between the groups at the start of the treatment (T1) are shown in Table 1. The evaluation of the mean values between the 


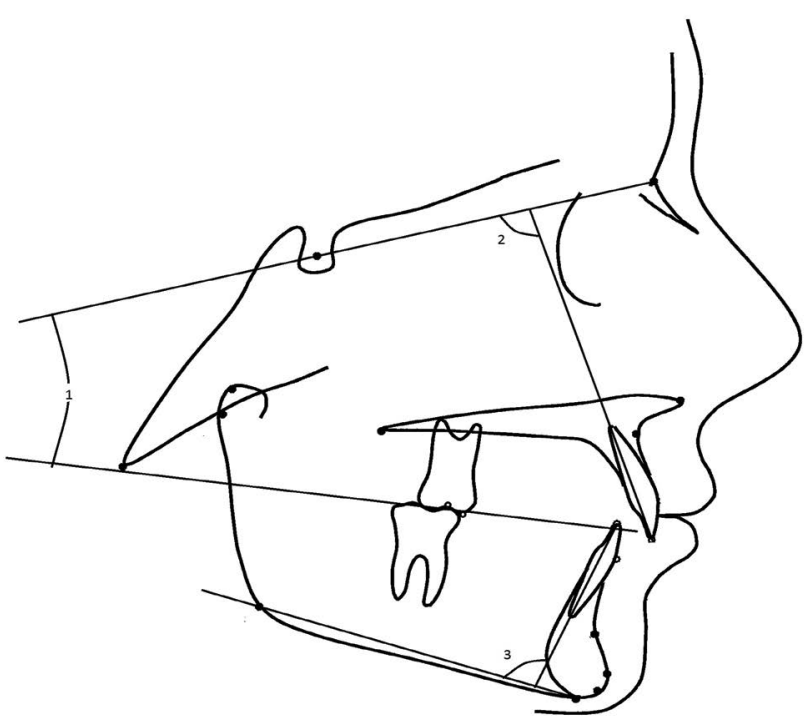

Figure 8: Dental angular measurements: 1) SN/OP; 2) U1/ SN; 3) IMPA.

Table 1: The comparison of the mean values of the dentoskeletal variables at T1 between the groups.

\begin{tabular}{|c|c|c|c|c|c|c|}
\hline Measurements & Groups & $\mathbf{N}$ & $\mathbf{x}$ & S.d. & $\mathbf{t}$ & $\mathbf{p}$ \\
\hline \multirow[t]{2}{*}{ SNA } & Monoblock & 10 & 81.69 & 4.51 & 1.09 & 0.287 \\
\hline & Twin Force & 10 & 79.88 & 2.62 & & \\
\hline \multirow[t]{2}{*}{ SNB } & Monoblock & 10 & 75.30 & 4.26 & 0.65 & 0.522 \\
\hline & Twin Force & 10 & 74.30 & 2.28 & & \\
\hline \multirow[t]{2}{*}{ ANB } & Monoblock & 10 & 6.39 & 1.36 & 0.65 & 0.522 \\
\hline & Twin Force & 10 & 5.58 & 1.65 & & \\
\hline \multirow[t]{2}{*}{ SN/PP } & Monoblock & 10 & 7.98 & 3.28 & 0.90 & 0.377 \\
\hline & Twin Force & 10 & 9.49 & 4.11 & & \\
\hline \multirow[t]{2}{*}{ SN/MP } & Monoblock & 10 & 31.93 & 5.15 & 1.61 & 0.123 \\
\hline & Twin Force & 10 & 35.02 & 3.13 & & \\
\hline \multirow[t]{2}{*}{ Co-A } & Monoblock & 10 & 83.76 & 4.44 & 1.22 & 0.237 \\
\hline & Twin Force & 10 & 81.32 & 4.46 & & \\
\hline \multirow[t]{2}{*}{ Co-Gn } & Monoblock & 10 & 106.34 & 4.17 & 1.18 & 0.855 \\
\hline & Twin Force & 10 & 106.00 & 4.05 & & \\
\hline \multirow[t]{2}{*}{$\mathrm{N}-\mathrm{Me}$} & Monoblock & 10 & 106.87 & 7.37 & 0.97 & 0.343 \\
\hline & Twin Force & 10 & 109.25 & 2.32 & & \\
\hline \multirow[t]{2}{*}{ S-Go } & Monoblock & 10 & 72.36 & 5.60 & 0.11 & 0.913 \\
\hline & Twin Force & 10 & 72.13 & 3.47 & & \\
\hline \multirow[t]{2}{*}{ Mst-SV } & Monoblock & 10 & 29.22 & 3.79 & 0.73 & 0.474 \\
\hline & Twin Force & 10 & 28.03 & 3.47 & & \\
\hline \multirow[t]{2}{*}{ Mit-SV } & Monoblock & 10 & 27.10 & 3.85 & 0.14 & 0.884 \\
\hline & Twin Force & 10 & 26.82 & 4.57 & & \\
\hline \multirow[t]{2}{*}{ Is-SV } & Monoblock & 10 & 59.32 & 4.16 & 1.67 & 0.112 \\
\hline & Twin Force & 10 & 55.90 & 4.94 & & \\
\hline \multirow[t]{2}{*}{ li-SV } & Monoblock & 10 & 52.17 & 4.05 & 0.79 & 0.439 \\
\hline & Twin Force & 10 & 50.50 & 5.30 & & \\
\hline \multirow[t]{2}{*}{ Overjet } & Monoblock & 10 & 8.47 & 2.52 & 2.07 & 0.057 \\
\hline & Twin Force & 10 & 6.58 & 1.38 & & \\
\hline \multirow[t]{2}{*}{ Overbite } & Monoblock & 10 & 4.56 & 3.15 & 1.24 & 0.228 \\
\hline & Twin Force & 10 & 2.16 & 1.62 & & \\
\hline \multirow[t]{2}{*}{ U1/SN } & Monoblock & 10 & 107.91 & 6.65 & 0.59 & 0.562 \\
\hline & Twin Force & 10 & 105.69 & 9.82 & & \\
\hline \multirow[t]{2}{*}{ IMPA } & Monoblock & 10 & 98.42 & 6.01 & 1.52 & 0.145 \\
\hline & Twin Force & 10 & 94.28 & 6.12 & & \\
\hline
\end{tabular}

$p<0.05$.
Table 2: The comparison of the mean values of the dentoskeletal variables at T2 between the groups.

\begin{tabular}{|c|c|c|c|c|c|c|}
\hline Measurements & Groups & $\mathbf{N}$ & $\mathbf{x}$ & S.d & $\mathbf{t}$ & $\mathbf{p}$ \\
\hline \multirow[t]{2}{*}{ SNA } & Monoblock & 10 & 81.01 & 4.43 & 1.05 & 0.306 \\
\hline & Twin Force & 10 & 79.35 & 2.27 & & \\
\hline \multirow[t]{2}{*}{ SNB } & Monoblock & 10 & 76.84 & 4.20 & 0.44 & 0.664 \\
\hline & Twin Force & 10 & 75.15 & 2.59 & & \\
\hline \multirow[t]{2}{*}{ ANB } & Monoblock & 10 & 4.21 & 1.84 & 0.82 & 0.426 \\
\hline & Twin Force & 10 & 4.20 & 1.61 & & \\
\hline \multirow[t]{2}{*}{ SN/PP } & Monoblock & 10 & 8.44 & 3.19 & 1.02 & 0.321 \\
\hline & Twin Force & 10 & 9.97 & 3.50 & & \\
\hline \multirow[t]{2}{*}{ SN/MP } & Monoblock & 10 & 32.49 & 5.01 & 1.82 & 0.085 \\
\hline & Twin Force & 10 & 35.94 & 3.27 & & \\
\hline \multirow[t]{2}{*}{ Co-A } & Monoblock & 10 & 83.75 & 4.59 & 1.17 & 0.254 \\
\hline & Twin Force & 10 & 81.36 & 4.47 & & \\
\hline \multirow[t]{2}{*}{ Co-Gn } & Monoblock & 10 & 110.11 & 3.96 & 1.35 & 0.194 \\
\hline & Twin Force & 10 & 107.55 & 4.49 & & \\
\hline \multirow[t]{2}{*}{$\mathrm{N}-\mathrm{Me}$} & Monoblock & 10 & 111.23 & 5.73 & 0.09 & 0.924 \\
\hline & Twin Force & 10 & 111.42 & 2.40 & & \\
\hline \multirow[t]{2}{*}{ S-Go } & Monoblock & 10 & 75.38 & 5.61 & 0.87 & 0.394 \\
\hline & Twin Force & 10 & 73.55 & 3.50 & & \\
\hline \multirow[t]{2}{*}{ Mst-SV } & Monoblock & 10 & 28.20 & 3.91 & 0.76 & 0.452 \\
\hline & Twin Force & 10 & 26.85 & 3.93 & & \\
\hline \multirow[t]{2}{*}{ Mit-SV } & Monoblock & 10 & 30.46 & 3.33 & 0.30 & 0.763 \\
\hline & Twin Force & 10 & 29.90 & 4.72 & & \\
\hline \multirow[t]{2}{*}{ İs-SV } & Monoblock & 10 & 57.53 & 3.96 & 2.01 & 0.059 \\
\hline & Twin Force & 10 & 53.55 & 4.82 & & \\
\hline \multirow[t]{2}{*}{ İi-SV } & Monoblock & 10 & 54.59 & 3.54 & 0.62 & 0.543 \\
\hline & Twin Force & 10 & 53.30 & 5.54 & & \\
\hline \multirow[t]{2}{*}{ Overjet } & Monoblock & 10 & 3.63 & 1.70 & 4.55 & $0.001^{*}$ \\
\hline & Twin Force & 10 & 0.39 & 1.46 & & \\
\hline \multirow[t]{2}{*}{ Overbite } & Monoblock & 10 & 1.29 & 2.05 & 4.26 & $0.001^{*}$ \\
\hline & Twin Force & 10 & -0.81 & 1.04 & & \\
\hline \multirow[t]{2}{*}{ U1/SN } & Monoblock & 10 & 102.60 & 6.27 & 1.06 & 0.300 \\
\hline & Twin Force & 10 & 99.16 & 8.02 & & \\
\hline \multirow[t]{2}{*}{ IMPA } & Monoblock & 10 & 102.33 & 5.28 & 0.72 & 0.478 \\
\hline & Twin Force & 10 & 104.42 & 7.42 & & \\
\hline
\end{tabular}

${ }^{*} p<0.05$

groups at the end of the treatment (T2) are shown in Table 2. The evaluation of the treatment period (T1 -T2) is presented in Table 3.

Both appliances were effective in inhibiting maxillary and sagittal growth and stimulating mandibular sagittal growth.

\section{Skeletal changes}

SNA angle decreased significantly in both groups (Table 3).

SNB angle showed a significant increase in both groups (Table 3).

ANB angle decreased in both groups. However, the difference between the groups was significant (Table 3).

SN/PP angle increased significantly in the Monoblock group, while it did not change in the Twin Force group (Table 3).

SN/MP angle increased significantly in both groups (Table 3). 
Co-A distance showed no change in both groups (Table 3).

Co-Gn distance increased significantly in both groups. However, the difference between the groups was significant (Table 3 ).

$\mathrm{N}$-Me distance showed a significant increase in both groups (Table 3).

S-Go distance increased significantly in both groups (Table 3).

\section{Dentoalveolar changes}

Mst-SV distance decreased significantly in both groups (Table 3).

Mit-SV distance showed a significant increase in both groups (Table 3).

Is-SV distance decreased significantly in both groups (Table 3).

li-SV distance showed a significant increase in both groups (Table 3).

Overjet and overbite were reduced significantly in both groups (Table 3 ).

Maxillary incisors retroclined significantly in both groups (Table 3).

Mandibular incisors showed significant proclination in both groups (Table 3).

\section{Discussion}

Class II malocclusions show the highest prevalence in orthodontics.

Treatments of Class II malocclusions were collected in 3 groups. These were: Dental camouflage therapy, surgical treatment and functional treatment [6].

In this study, the effects of Monoblock and Twin Force appliances on dentofacial structures used in functional therapy were evaluated.

The SNA angle decreased in both groups. Decrease in the SNA angle in both groups suggests maxillary inhibition of sagittal development for both appliances. Our findings were consistent with those of other studies [7-10]. However, some authors observed significant changes in the SNA angle [11-14].

The increase in the SNB angle in both groups suggested stimulation of sagittal mandibular development in both appliances. In other studies, the SNB angle was also showed to increase [7-9,15].

The ANB angle showed a significant increase in both groups. Other studies supported our findings $[10,14,16]$. It maybe deduced that the ANB angle decreased due to the maxillary inhibition of sagittal development and stimulation of sagittal mandibular development.

The SN/PP angle showed a significant increase in
Table 3: The comparison of the changes before and after the treatment period.

\begin{tabular}{|c|c|c|c|c|c|c|}
\hline Measurements & Groups & $\mathbf{N}$ & D & S.d & $\mathbf{t}$ & p \\
\hline \multirow[t]{2}{*}{ SNA } & Monoblock & 10 & 0.68 & 0.42 & 0.59 & 0.557 \\
\hline & Twin Force & 10 & 0.53 & 0.66 & & \\
\hline \multirow[t]{2}{*}{ SNB } & Monoblock & 10 & -1.54 & 0.76 & 0.62 & 0.543 \\
\hline & Twin Force & 10 & -0.85 & 1.38 & & \\
\hline \multirow[t]{2}{*}{ ANB } & Monoblock & 10 & 2.18 & 0.78 & 4.92 & $0.001^{*}$ \\
\hline & Twin Force & 10 & 1.38 & 1.35 & & \\
\hline \multirow[t]{2}{*}{ SN/PP } & Monoblock & 10 & -0.46 & 0.47 & 0.05 & 0.954 \\
\hline & Twin Force & 10 & -0.48 & 0.96 & & \\
\hline \multirow[t]{2}{*}{ SN/MP } & Monoblock & 10 & -0.56 & 0.34 & 1.44 & 0.165 \\
\hline & Twin Force & 10 & -0.92 & 0.70 & & \\
\hline \multirow[t]{2}{*}{ Co-A } & Monoblock & 10 & 0.01 & 0.32 & 0.30 & 0.764 \\
\hline & Twin Force & 10 & -0.04 & 0.40 & & \\
\hline \multirow[t]{2}{*}{ Co-Gn } & Monoblock & 10 & -3.77 & 2.01 & 3.09 & $0.006^{*}$ \\
\hline & Twin Force & 10 & -1.55 & 1.03 & & \\
\hline \multirow[t]{2}{*}{$\mathrm{N}-\mathrm{Me}$} & Monoblock & 10 & -4.36 & 3.11 & 2.14 & 0.057 \\
\hline & Twin Force & 10 & -2.17 & 0.89 & & \\
\hline \multirow[t]{2}{*}{ S-Go } & Monoblock & 10 & -3.02 & 2.73 & 1.79 & 0.089 \\
\hline & Twin Force & 10 & -1.42 & 0.67 & & \\
\hline \multirow[t]{2}{*}{ Mst-SV } & Monoblock & 10 & 1.02 & 0.82 & 0.42 & 0.673 \\
\hline & Twin Force & 10 & 1.18 & 0.84 & & \\
\hline \multirow[t]{2}{*}{ Mit-SV } & Monoblock & 10 & -3.36 & 1.16 & 0.07 & 0.944 \\
\hline & Twin Force & 10 & -3.28 & 3.35 & & \\
\hline \multirow[t]{2}{*}{ Is-SV } & Monoblock & 10 & 1.79 & 1.00 & 0.93 & 0.360 \\
\hline & Twin Force & 10 & 2.35 & 1.59 & & \\
\hline \multirow[t]{2}{*}{ li-SV } & Monoblock & 10 & -2.42 & 1.05 & 0.68 & 0.502 \\
\hline & Twin Force & 10 & -2.80 & 1.39 & & \\
\hline \multirow[t]{2}{*}{ Overjet } & Monoblock & 10 & 4.84 & 2.07 & 1.56 & 0.136 \\
\hline & Twin Force & 10 & 6.19 & 1.78 & & \\
\hline \multirow[t]{2}{*}{ Overbite } & Monoblock & 10 & 3.27 & 3.04 & 0.60 & 0.554 \\
\hline & Twin Force & 10 & 2.97 & 1.94 & & \\
\hline \multirow[t]{2}{*}{ U1/SN } & Monoblock & 10 & 5.31 & 4.08 & 0.56 & 0.591 \\
\hline & Twin Force & 10 & 6.53 & 5.75 & & \\
\hline \multirow[t]{2}{*}{ IMPA } & Monoblock & 10 & -3.91 & 2.43 & 2.99 & $0.011^{*}$ \\
\hline & Twin Force & 10 & -10.14 & 6.11 & & \\
\hline
\end{tabular}

${ }^{*} p<0.05$

the Monoblock group, while it did not change in the Twin Force group. Some researchers [17-19] observed increases in this angle, as in our case. However, other researchers observed no change in this angle $[12,13,20]$.

The SN/MP angle showed a significant increase in both groups. Some researchers $[9,12,21]$ observed that this angle increased significantly as ours, whereas others $[13,14,22]$ observed no change in this angle. Harvold and Vargerik [23] deduced that the height of the posterior alveolar processes and the amount of eruption of the teeth in the posterior segment increased, and a posterior mandibular rotation occurred. We may conclude that the posterior rotation of the mandible increased the SN/MP angle in our study.

Co-A distance did not change in either group. Our findings were supported by different studies $[11,24,25]$. However, other researchers observed an increase in this distance $[26,27]$. No significant change in the Co-A value in the groups of our study was attributed to the absence of a significant increase in condylar growth in the sagittal direction. 
The increase in the distance of Co-Gn in both groups in our study supports the opinion that the lower jaw moved forward. The increase in the Monoblock group was greater than the increase in the Twin Force group. This could be attributed to the shorter treatment times in the Twin Force group.

There are controversial views on the mandibular effects of functional appliances. Different studies support our findings $[14,15,24,28]$. However, Chen, et al. [29] reported that the clinical effects of functional appliances on mandibular development were limited. Some authors $[9,22,30]$ also indicated that the fixed functional appliance did not change the mandibular length.

The $\mathrm{N}$-Me distance showed an increase in both groups. While some researchers $[8,28,31]$ observed am increase in this distance, Valant and Sinclair [16] observed no change in this distance.

The S-Go distance increased in both groups. Our findings were consistent with those of other studies $[14,26,27]$.

The Mst-SV distance decreased in both groups. The decrease of this distance was supported by previous studies [12,22]. However, other researchers [11,32] reported that the upper molar teeth were mesialized due to growth and development, and they were not affected by the treatment.

The Mit-SV distance increased in both groups. Our findings were consistent with those of different studies $[11,13,22,26]$.

The Is-SV distance decreased in both groups. While some researchers $[12,26]$ recorded a decrease in this distance, Cozza [11] recorded no significant change in this distance.

The li-SV distance increased in both groups. Different studies supported our findings $[14,27,33]$.

Overjet showed a significant decrease in both groups. Some researchers $[34,35]$ claimed that the decrease in the degree of overjet depends on the change of dentoalveolar structures during the treatment period. In this study, the reduction in overjet was due to retraction of the upper incisor teeth, protrusion of the lower incisor teeth and prepositioning of mandibular. The decrease in overjet was supported by previous studies $[9,12,22,33]$.

Overbite decreased in both groups. In both groups, lower incisor protrusion and increase in mandibular length resulted in a reduction in the amount of overbite. Many researchers observed a decrease in overbite in their studies [11,12,24].

The U1/SN angle significantly decreased in both groups.
These findings indicated that the upper incisor teeth were retroclined in both groups. The decrease in this angle was seen in previous studies $[8,12,22,33]$.

However, Dalci, et al. [14] an observed insignificant change in this angle in a Twin Force group, and they attributed the insignificant retrusion to upper palatal torque applied by the fixed appliances and the shorter treatment period for their Twin Force group.

IMPA showed a significant increase in both groups. The increase in the Twin Force group was greater than the increase in the Monoblock group. It maybe concluded that the dentoalveolar effect of Twin Force was greater than that of the Monoblock. Our findings were supported by previous studies $[12,19,22,33]$. However, other researchers observed no change in this angle $[8,11,13]$.

\section{Conclusion}

Both appliances were found to be effective in Class II Div. 1 malocclusion correction, but it was found that more skeletal effect was obtained in the Monoblock group. While the Monoblock appliance was a successful choice in case of desiring more skeletal impact, The Twin Force appliance was an alternative choice in the case of lack of cooperation. There was a need for more comprehensive future studies to evaluate a fixed functional appliance and a removable functional appliance.

\section{References}

1. Sayin MO, Türkkahraman H (2004) Malocclusion and crowding in an orthodontically referred Turkish population. Angle Orthod 74: 635-639.

2. Turkkahraman H, Eliacik SK, Findik Y (2016) Effects of miniplate anchored and conventional forsus fatigue resistant devices in the treatment of class ii malocclusion. Angle Orthod 86: 1026-1032.

3. Abdulfatah Hanoun, Thikriat S Al-Jewair, Sawsan Tabbaa, Mhd Amer Allaymouni, Charles B Preston (2014) A comparison of the treatment effects of the forsus fatigue resistance device and the twin block appliance in patients with class ii malocclusions. Clin Cosmet Investig Dent 6: 57.

4. Teuscher $U$ (1986) An appraisal of growth and reaction to extraoral anchorage. Simulation of orthodontic-orthopedic results. Am J Orthod 89: 113-121.

5. Oliveira de JN Jr, Rodrigues de Almeida R, Rodrigues de Almeida M, de Oliveira JN (2007) Dentoskeletal changes induced by the Jasper jumper and cervical headgear appliances followed by fixed orthodontic treatment. Am J Orthod Dentofacial Orthop 132: 54-62.

6. Pancherz H, Ruf S (2000) The herbst appliance: Researchbased updated clinical possibilities. World Journal of Orthodontics 1.

7. Pancherz H (1984) A cephalometric analysis of skeletal and dental changes contributing to class ii correction in activator treatment. AJODO 85: 125-134.

8. Sari Z, Goyenc Y, Doruk C, Usumez S (2003) Comparative evaluation of a new removable jasper jumper functional 
appliance vs an activator-headgear combination. Angle Orthod 73: 286-293.

9. Cope JB, Buschang PH, Cope DD, Parker J, Blackwood HO (1994) Quantitative evaluation of craniofacial changes with jasper jumper therapy. Angle Orthod 64: 113-122.

10. Weiland FJ, Bantleon HP (1995) Treatment of class ii malocclusions with the jasper jumper appliance-a preliminary report. AJODO 108: 341-350.

11. Cozza P, De Toffol L, Colagrossi S (2004) Dentoskeletal effects and facial profile changes during activator therapy. Eur J Orthod 26: 293-302.

12. Tümer N, Gültan AS (1999) Comparison of the effects of monoblock and twin-block appliances on the skeletal and dentoalveolar structures. Am J Orthod Dentofacial Orthop 116: $460-468$.

13. Doruk C, Göyenç $Y$ (1999) Geç dönem angle sınıf ii, bölüm 1 maloklüzyonlu bireylerde fonksiyonel tedavinin değerlendirilmesi. Cumhuriyet Dent J 2: 64-70.

14. Dalci O, Altug AT, Memikoglu UT (2014) Treatment effects of a twin-force bite corrector versus an activator in comparison with an untreated class ii sample: A preliminary report. Aust Orthod J 30: 45-53.

15. Chang HF, Kai-ming WU, Chen KC, Cheng MC (1989) Effects of activator treatment on class ii, division 1 malocclusion. JCO 23: 560 .

16. Valant JR, Sinclair PM (1989) Treatment effects of the herbst appliance. Am J Orthod Dentofacial Orthop 95: 138147.

17. Cozza P, Polimeni A, Ballanti F (2004) A modified monobloc for the treatment of obstructive sleep apnoea in paediatric patients. Eur J Orthod 26: 523-530.

18. Pancherz H (1979) Treatment of class ii malocclusions by jumping the bite with the herbst appliance: A cephalometric investigation. Am J Orthod 76: 423-442.

19. Nelson BK, Hansen, Hägg U (2000) Class ii correction in patients treated with class ii elastics and with fixed functional appliances: A comparative study. Am J Orthod Dentofacial Orthop 118: 142-149.

20. Küçükkeleş N, İlhan I, Orgun İA (2007) Treatment efficiency in skeletal class ii patients treated with the jasper jumper: $\mathrm{A}$ cephalometric evaluation. Angle Orthod 77: 449-456.

21. Nelson C, Harkness M, Herbison P (1993) Mandibular changes during functional appliance treatment. $A m \mathrm{~J}$ Orthod Dentofacial Orthop 104: 153-161.
22. Covell Jr DA, Trammell DW, Boero RP, West R (1999) A cephalometric study of class ii division 1 malocclusions treated with the Jasper Jumper appliance. Angle orthod 69: 311-320.

23. Harvold EP, Vargervik K (1971) Morphogenetic response to activator treatment. AJODO 60: 478-490.

24. Basciftci FA, Uysal T, Büyükerkmen A, Sari Z (2003) The effects of activator treatment on the craniofacial structures of class ii division 1 patients. Eur J Orthod 25: 87-93.

25. de Almeida MR, Henriques JF, de Almeida RR, Weber U, McNamara Jr JA (2005) Short-term treatment effects produced by the herbst appliance in the mixed dentition. Angle Orthod 75: 540-547.

26. Karacay S, Akin E, Olmez H, Gurton AU, Sagdic D (2006) Forsus nitinol flat spring and jasper jumper corrections of class ii division 1 malocclusions. Angle Orthod 76: 666-672.

27. Türkkahraman H, Sayın MÖ (2005) Effects of activator and activator headgear treatment: Comparison with untreated class ii subjects. Eur J Orthod 28: 27-34.

28. Stromeyer EL, Caruso JM, DeVincenzo JP (2002) A cephalometric study of the class ii correction effects of the Eureka spring. Angle Orthod 72: 203-210.

29. Chen JY, Will LA, Niederman R (2002) Analysis of efficacy of functional appliances on mandibular growth. Am J Orthod Dentofacial Orthop 122: 470-476.

30. Nalbantgil D, Arun T, Sayinsu K, Fulya I (2005) Skeletal, dental and soft-tissue changes induced by the jasper jumper appliance in late adolescence. Angle Orthod 75: 426-436.

31. Jakobsson SO, Paulin G (1990) The influence of activator treatment on skeletal growth in angle class ii: 1 case. A roentgenocephalometric study. Eur J Orthod 12: 174-184.

32. Wieslander $L$ (1984) Intensive treatment of severe class ii malocclusions with a headgear-herbst appliance in the early mixed dentition. Am J Orthod 86: 1-13.

33. Heinig N, Göz G (2001) Clinical application and effects of the forsus spring. A study of a new herbst hybrid. J Orofac Orthop 62: 436-450.

34. Wieslander L, Lagerström $L$ (1979) The effect of activator treatment on class ii malocclusions. Am J Orthod 75: 20-26.

35. Vargervik K, Harvold EP (1985) Response to activator treatment in class ii malocclusions. Am J Orthod 88: 242251. 